\title{
Transparent Texts
}

\author{
Authors of Scientific Articles Often Have Conflicts of Interest. \\ It Is Important for These to Be Communicated Transparently to the Readers.
}

$(2$ ince 2005, Deutsches Ärzteblatt has required authors of scientific articles to submit a declaration of conflicts of interest. We publish this information together with the article itself, even when the author has stated that no conflicting interests are present. Our readers have welcomed this change, and most authors, too, are in favor of communicating conflicts of interest transparently.

Nonetheless, we are still regularly confronted with misunderstandings and inquiries on the subject. We have therefore decided to explain in detail here what, exactly, the medical-scientific editorial office (under the heading "Medicine") considers to be an authorial conflict of interest; what our experience in this matter has been over the past three years; and what inferences a reader should—and should not—-draw from the declared presence of such a conflict. First of all, though, a few words are in order about the scientific background of the discussion of conflicts of interest.

\section{"He who pays the piper, calls the tune"?}

Conflicts of interest have been defined in more than one way, but the common element of all definitions is that a conflict of interest exists when one intention, such as that of helping a patient or solving a scientific problem, might be negatively affected by another, such as that of acquiring financial gain (1). The following brief selection of research results shows the extent to which opposing interests of this kind can be reflected in a distortion of the content of scientific publications:

- In a study of fundamental importance, Stelfox and colleagues (2) investigated the relationship between the conclusions of articles on calcium antagonists and the financial ties of their authors to drug manufacturers. The data that were studied included, on the one hand, 70 original and review articles, and letters to the editor about calcium antagonists, and, on the other hand, all of the authors' responses to a questionnaire about conflicts of interest that was sent to them by the study team. Stelfox and his coauthors classified each text as being positive, negative, or neutral with respect to calcium antagonists. It turned out that authors of positive articles had financial ties to the manufacturers much more commonly (96\%) than did the authors of neutral (60\%) or critical articles (37\%). The authors of critical articles, however, did not have material relationships to competing companies any more commonly than the authors of positive articles.

- Friedman and Richter (3) analyzed all 398 original articles that appeared in the New England Journal of Medicine and the JAMA in 2001. A conflict of interest was present in $38.7 \%$ of these articles. Even after other possible influences such as case numbers, study design, and country of origin were accounted for, there was still a statistically significant association between conflicts of interest and positive study results (odds ratio, 2.35; 95\% confidence interval, 1.08-5.09).

- Roy Perlis and his research group (4) studied 162 randomized, placebo-controlled trials in the psychiatric literature and found a statistically significant association between positive study findings and a conflict of interest of at least one author (odds ratio, 8.4; 95\% confidence interval, 2.6-27.3).

Other studies have confirmed these results, albeit with methods that did not permit a separate analysis of the effects of clinical study financing and of authorial conflicts of interest (for examples, see [5-10]; [11] was one of the few negative studies. For a review, see [12]). When study results are reported to be correlated with authorial conflicts of interest taken together with sources of study financing, there is no way to determine precisely what part of this correlation is due to the conflicts of interest alone. A number of studies of this type are briefly summarized in table 1.

The studies published so far indicate that conflicts of interest seem to be associated with the tenor of articles on therapeutic, diagnostic, and cost-effectiveness studies, and this association is not solely due to collaboration with the pharmaceutical industry alone. There is evidence, for example, that the tobacco industry has also succeeded in influencing scientists $(7,8,13)$. It seems plausible to infer that no medical specialty is impervious to conflicts of interest and their effects. Moreover, this finding holds not just for original articles, but even for literature reviews - a fact that is of particular importance to Deutsches Ärzteblatt, because many of our articles are currently of this type. A study of review articles on the health hazards of passive smoking, for example, revealed that the authors' collaboration with the tobacco industry was highly correlated with a negative finding (13). 
TABLE 1

Selected investigations of the association between conflicts of interest and study financing on the one hand, and study findings on the other

\begin{tabular}{l|l|l}
$\begin{array}{l}\text { Study authors } \\
\begin{array}{l}\text { Stelfox et al., } \\
1998 \text { (2) }\end{array}\end{array}$ & $\begin{array}{l}\text { Study subject } \\
\text { Results }\end{array}$ \\
\hline $\begin{array}{l}\text { Friedman \& Richter, } \\
2004 \text { (3) }\end{array}$ & $\begin{array}{l}\text { 398 original articles from the JAMA and } \\
\text { the New England Journal of Medicine }\end{array}$ & $\begin{array}{l}\text { Articles tending to support the use of calcium antagonists were } \\
\text { more frequently written by authors with connections to the } \\
\text { manufacturers than critical articles were. }\end{array}$ \\
\hline $\begin{array}{l}\text { Perlis et al., } \\
2005 \text { (4) }\end{array}$ & $\begin{array}{l}162 \text { randomized controlled trials on } \\
\text { psychiatric treatment }\end{array}$ & Conflicts of interest were associated with positive study findings. \\
\hline $\begin{array}{l}\text { Kjaergard \& } \\
\text { Alt-Nielsen, } \\
2002 \text { (5) }\end{array}$ & $\begin{array}{l}159 \text { randomized controlled trials } \\
\text { appearing in the BMJ from } 1997 \text { to } 2001\end{array}$ & Conflicts of interest were associated with positive conclusions. \\
\hline $\begin{array}{l}\text { Jørgensen et al., } \\
2007 \text { (10) }\end{array}$ & 143 articles on mammography & $\begin{array}{l}\text { The authors' specialties were associated with the presentation of } \\
\text { benefits vs. risks of mammography. }\end{array}$ \\
\hline $\begin{array}{l}\text { Barnes \& Bero, } \\
1998 \text { (13) }\end{array}$ & 106 review articles on passive smoking & $\begin{array}{l}\text { The authors' collaboration with the tobacco industry was correlated } \\
\text { with the view that passive smoking is harmless. }\end{array}$ \\
\hline $\begin{array}{l}\text { Bell et al., } \\
2008 \text { (6) }\end{array}$ & $\begin{array}{l}494 \text { original articles on } \\
\text { cost-effectiveness }\end{array}$ & $\begin{array}{l}\text { Industry-financed studies were less critical regarding } \\
\text { cost-effectiveness. }\end{array}$ \\
\hline $\begin{array}{l}\text { Yank et al., } \\
2007 \text { (24) }\end{array}$ & $\begin{array}{l}124 \text { meta-analyses on the treatment } \\
\text { of hypertension }\end{array}$ & $\begin{array}{l}\text { Financial ties to a pharmaceutical company were associated } \\
\text { with positive conclusions. }\end{array}$ \\
\hline
\end{tabular}

A selection of eight investigations regarding the association between conflicts of interest and study financing on the one hand, and study findings on the other Important note on methods: Among the research projects in the above table, only the first three took separate account of the authors' conflicts of interest and of study financing. The rest considered these two factors together.

The purpose of this table is to illustrate the broad spectrum of subjects in which scientific reporting has been shown to be affected by conflicts of interest.

\section{Consequences}

It has thus been well established that the presence of a conflict of interest can affect the results of a study or the conclusions of an article, though one must not forget that not all publications by authors with conflicts of interest are necessarily biased. The danger of distortion is real, in any case, and has led to the introduction of declarations of conflicts of interest so that the readers can be aware of the authors' potential entanglements. The New England Journal of Medicine was the pioneer in this matter when it began to require conflict of interest declarations in 1984; many other journals have followed its lead since then. A larger percentage of medical journals than of journals in any other area have adopted rules for dealing with conflicts of interest (14).

Nonetheless, even in the medical field, declarations of conflicting interests cannot be taken for granted. Schneider and colleagues $(15,16)$, for example, found that only 18 of 31 journals in the area of health services research required their authors to declare conflicts of interest. Among medical periodicals that require such declarations, only $60 \%$ published them with every article (17).

\section{Consequences for Deutsches Ärzteblatt}

Since 2002, the instructions for authors of Deutsches Ärzteblatt has contained a requirement to inform the editors of any conflict of interest. Since 2005, we have also required a written declaration of all such conflicts. In so doing, we use the definition of conflicts of interest that was proposed by the International Committee of Medical Journal Editors (ICMJE) (18) (box). Unlike many other journals, we require a declaration from every author, and not just from the corresponding author of each article. Furthermore, the rule applies to all kinds of contributions, including letters to the editor that are to be published in the "Correspondence" section. All manuscript reviewers are also asked about conflicting interests. Finally, when an editor has a conflict of interest, the manuscript is given to another editor for processing.

\section{Initial experience at Deutsches Ärzteblatt}

In 2006 and 2007, at least one author declared a conflict of interest in 65 of the 207 original and review articles (31.4\%) that were published in Deutsches Ärzteblatt under the heading "Medicine." Among the 746 authors of articles published in these two years, nearly one in five declared a conflict ( $n=140,18.8 \%$ ). The great majority of such conflicts involved financial ties to the pharmaceutical industry. In comparison, not a single original or review article appearing in Deutsches Ärzteblatt in 2002 and 2003 was accompanied by a declaration of an existing conflict of interest (table 2).

Our current figures are of comparable magnitude to those of Deutsche Medizinische Wochenschrift $(D M W)$, which documented the presence of conflicts of interest in one-third (34.3\%) of its original and review articles appearing in 2006 and 2007 (table 2). The percentage of declared conflicts of interest in the 
DMW was considerably lower in 2002 and 2003, at only 9.2\%; thus, authors' positive declarations became considerably more common over this period of time, even though the DMW did not alter its method of eliciting such declarations between 2002 and 2007 (personal communication from Dr. Hirschel, Deputy Editor-inChief of the DMW). Like Deutsches Ärzteblatt, the $D M W$ requires all authors to declare all conflicts of interest in writing. The increased frequency of positive declarations of conflicts of interest is perhaps partly due to an actual increase in the number of such conflicts, but it may also reflect a greater readiness on the authors' part to provide transparent information. In recent years, too, the definition of conflicts of interest seems to have become better understood, and the public's consciousness of this matter seems to have been raised. The increase in the number of declared conflicts of interest in Deutsches Ärzteblatt since 2002/2003 is certainly also due to the introduction of a mandatory written declaration for every article.

\section{Authors who give false information}

Readers view articles with conflicts of interest more critically than articles without them (19), yet we think that the transparent communication of colliding interests ought to be a component of every scientific article. This is also a legitimate demand of the public at large, which pays for the health care system. An obligation to deal with conflicts of interest appropriately has been incorporated into the "Charter on Medical Professionalism" of the international Medical Professionalism Project (20).

We count on our authors' cooperation. We realize that we usually cannot check what our authors tell us, and that conflicts of interest can be concealed. In this connection, Goozner (21), in a study of four American journals, found that a conflict of interest that should have been declared went unmentioned in approximately every tenth to every twentieth article. One reason for this may have been that some authors considered the benefits they had received to have had no influence on their medical judgment. Subjective assessments of this type, however, are separate from the basic question of whether a conflict of interest exists; here, the only relevant issue at hand is whether financial or other connections are present. Journals can do no more than ask their authors openly and then hope that they will volunteer the correct information, though a future collaboration based on trust is certainly endangered when an author has already given false information on one occasion.

\section{What does a conflict of interest mean?}

Although the requirement to declare conflicts of interest has generally been positively received by readers of Deutsches Ärzteblatt, some readers have registered discontent with it. One private practitioner, for example, wrote us in 2006: "You have taken a good first step by naming the authors' financial backers from industry. Now take the second step and stop publishing articles by 'sponsored' authors entirely."

\section{TABLE 2}

Conflicts of interest in articles appearing in Deutsches Ärzteblatt (DÄ) and in the Deutsche Medizinische Wochenschrift (DMW)

\begin{tabular}{l|c|c|c|c} 
& \multicolumn{2}{|c|}{$2006-2007$} & \multicolumn{2}{c|}{$2002-2003$} \\
& 207 & 233 & 220 & 250 \\
\hline $\begin{array}{l}\text { Total number of original } \\
\text { and review articles }\end{array}$ & 207 & & & \\
\hline $\begin{array}{l}\text { Number of original and } \\
\text { review articles with existing, } \\
\text { declared conflicts of interest }\end{array}$ & $(31.4 \%)$ & $(34.3 \%)$ & 0 & 23 \\
& & & & \\
\hline
\end{tabular}

The table shows the percentage of original and review articles for which at least one author declared an existing conflict of interest. For the purpose of this table, the articles were classed as they had been originally categorized by the journal editors.

Is this reader right? Does a conflict of interest really invalidate the content of an article? We in the MedicalScientific Editorial Office think the answer is no. To give an example from clinical practice: A physician may come into a conflict of interest by offering a medical service that is unnecessary for the patient, but lucrative to him- or herself. There are presumably some physicians who would actually deliver the service in such a case. Many, however, solve the conflict by restricting themselves to their medical role and refraining from the needless treatment. This example shows that the mere presence of a conflict of interest does not necessarily entail improper behavior.

Generalizing this concept to the field of medical publishing, we can say that a conflict of interest is not synonymous with distorted judgment, or with a bad article. Important as it is to be aware of the dangers that conflicts of interest present, it is just as important to remember that many articles by authors possessing such conflicts are, in fact, unbiased in their content. This, too, is a finding of the studies that were cited above. A conflict of interest is thus nothing dishonorable in itself, but the reader must always be able to obtain a clear picture of the colliding interests that are present. This is one of the main reasons why scholarly journals try to prevent distortions in the articles that they publish through editorial review and through the peer review process.

When evaluating conflicts of interest, one must keep in mind that some degree of cooperation between clinicians and scientists on the one hand, and the pharmaceutical industry and manufacturers of medical products on the other, is often desirable and sometimes inevitable. Scientists and clinically active physicians often play an essential role in the development of new medications, for example. This being the case, it is also only fair that those who make a real contribution should be adequately rewarded for their efforts.

Conflicts of interest are far from rare, not just in scholarly journals and in academic medicine, but in medicine in general. In an American study, 94\% of all physicians reported having some type of financial tie to the pharmaceutical industry, ranging from the receipt of 
BOX

\section{The conflict of interest declaration for authors submitting articles to the Medical-Scientific Editorial Board of Deutsches Arzteblatt}

The Medical-Scientific Editorial Board of Deutsches Ärzteblatt requires of all authors, including co-authors, a signed declaration of any existing conflicts of interest. This declaration must be in accordance with the definition of conflicts of interest proposed by the International Committee of Medical Journal Editors (ICMJE) (18) and must relate to the present and to the past five years. The Editorial Board's letter requesting the authors' disclosure contains the following statement, which provides examples of situations counting as conflicts of interest:

"A possible conflict of interests in the sense of the Uniform Requirements for Manuscripts Submitted to Biomedical Journals of the ICMJE (International Committee of Medical Journal Editors) exists if an author has financial or personal ties to third parties whose interests may be affected positively or negatively by the manuscript. Possible financial competing interests might be financial ties to organizations whose products are mentioned in the manuscript explicitly or implicitly. Such a company might be a pharmaceutical company, for example, which manufactures or trades in a drug mentioned in the manuscript, or a rival product. Financial ties include, for example, employment relations, advisory activities, holdings of stocks or shares, honoraria for lectures or presentations, reimbursement of travel expenses, study support, or other extrabudgetary support.

Nonfinancial conflicts of interests include, for example, close personal ties to someone whose scientific or personal affairs are affected by the article (partners, family ties, etc.)."

The authors' responses are published in a note at the end of each article, even if the authors have indicated that they have no conflict of interest. free samples and dinner invitations to lecture fees and consulting contracts (22). Even if the situation in Germany does not precisely correspond to that in the USA, we must assume that conflicts of interest are ubiquitous. In a certain sense, they are an inevitable accompaniment of health care delivery, as the clinical example above was meant to show. Nor should one forget that conflicts of interest of a nonfinancial sort can also imperil the scientific value of an article, even if such conflicts are much less frequently declared than financial ones, which are far easier to measure.

In view of the ubiquity of conflicts of interest, the New England Journal of Medicine has had to relax its previously strict rules for the authors of editorials and review articles. Its editors realized that, for certain important topics, authors without conflicts of interest could no longer be found. The New England Journal of Medicine, therefore, distinguishes various different types of conflict of interest (23), considering (for example) lecture fees to be less important than the possession of corporate stock. The British journal The Lancet operates similarly.

\section{What is to be done?}

As it would not be justified to reject articles solely because of their authors' conflicts of interest, reading critically is the only method we possess to detect when an article's content has truly been distorted. Critical reading, therefore, is a responsibility for the readers of Deutsches Ärzteblatt, just as it is for our editorial staff in the processing of manuscripts. Whenever a conflict of interest has, in fact, been declared to exist, it is prudent to adopt a skeptical attitude when reading a scientific article, even if this requires a bit of additional effortand no matter what journal the article is printed in.

\section{Conflict of interest statement}

The author is Chief Scientific Editor of Deutsches Ärzteblatt and Deutsches Ärzteblatt International.

\section{Acknowledgement}

The author thanks Professor Wolf-Dieter Ludwig (Berlin) for critically reviewing the manuscript.

Translated from the original German by Ethan Taub, M.D.

\section{REFERENCES}

1. Thompson D: Understanding financial conflicts of interest. N Engl J Med 1993; 329: 573 -6.

2. Stelfox HAT, Chua G, O'Rourke K, Detsky AS: Conflict of interest in the debate over calcium-channel antagonists. N Engl J Med 1998; 338: 101-106.

3. Friedmann LS, Richter ED: Relationship between conflicts of interest and research results. J Gen Intern Med 2004; 19: 51-6.

4. Perlis RH, Perlis CS, Wu Y, Hwang C, Joseph M, Nierenberg AA: Industry sponsorship and financial conflict of interest in the reporting of clinical trials in psychiatry. Am J Psychiatry 2005; 162: 1957-60.

5. Kjaergard LL, Als-Nielsen B: Association between competing interests and authors' conclusions: epidemiological study of randomized clinical trials published in the BMJ. BMJ 2002; 325: 249.

6. Bell CM, Urbach DR, Ray JG, Bayoumi A, Rosen AB, Greenberg D, Neumann PJ: Bias in published cost effectiveness studies: systematic review. BMJ 2006; 332: 699-703.

7. Bero LA, Glantz S, Hong MK. The limits of competing interest disclosures. Tobacco Control 2005; 14: 118-26.

8. Garne D, Watson M, Chapman S, Byrne F: Environmental tobacco smoke research published in the journal Indoor and Built Environment and associations with the tobacco industry. Lancet 2005 365: 804-09.

9. Tungaraza T, Poole R: Influence of drug company authorship and sponsorship on drug trial outcomes. Br J Psychiatry 2007; 191: 82-83.

10. Jørgensen KJ, Klahn A, Gøtzsche PC: Are benefits and harms in mammography screening given equal attention in scientific articles? A cross-sectional study. BMC Medicine 2007; 5:12.

11. Clifford TJ, Barrowman N, Moher D: Founding source, trial outcome and reporting quality: are they related? Results of a pilot study. BMC Health Services Research 2002; 2: 18.

12. Bekelman JE, Li Y, Gross CP: Scope and impact of financial conflicts of interest in biomedical research: a systematic review. JAMA 2003; 289: 454-65.

13. Barnes DE, Bero LA: Why review articles on the health effects of passive smoking reach different conclusions. JAMA 1998; 279: 1566-70.

14. Ancker JS, Flanagin A: A comparsion of conflict of interest policies at peer-reviewed journals in different scientific disciplines. Sci Eng Ethics 2007; 13: 147-57.

15. Schneider N, Lingner H, Schwartz FW: Disclosing conflicts of interest in German publications concerning health services research. BMC Health Services Research 2007; 7: 78 . 
16. Schneider N: Mehr Transparenz bei Interessenkonflikten. Dtsch Arztebl 2008; 108(18): 943-44.

17. Cooper RJ, Gupta M, Wilkes MS, Hoffmann JR: Conflict of interest disclosure policies and practices in peer-reviewed Biomedical journals. J Gen Intern Med 2006; 21: 1248-52.

18. ICMJE. Uniform requirements for manuscripts submitted to biomedical journals: Writing and editing for biomedical publication. I D: Conflicts of interest. http://www.icmje.org

19. Chaudhry S, Schroter S, Smith R, Morris J: Does declaration of competing interests affect readers' perceptions? A randomised trial. BMJ 2002; 325: 1391-2

20. Medical Professionalism Project. Medical professionalism in the new millennium: a physicians' charter. Lancet 2002; 359: $520-2$.

21. Goozner M: Unrevealed: Non-disclosure of conflicts of interests in four leading medical and scientific journals. Washington DC: Center for Science in the Public Interest 2004; www.espinet.org
22. Campbell EG, Gruen RL, Mountford J, Miller LG, Cleary PD, Blumenthal $D$ : An national survey of physician - industry relationships. N Engl J Med 2007; 356: 1742-50.

23. Drazen JM, Curfman GD. Financial associations of authors. N Engl J Med 2002; 364: 1901-2.

24. Yank V, Rennie D, Bero LA: Financial ties and concordance between results and conclusions in meta-analyses: retrospective cohort study. BMJ 2007; 335: 1202-5.

\section{PD Dr. med. Christopher Baethge}

Chief Scientific Editor

baethge@aerzteblatt.de

Dtsch Arztebl Int 2008; 105(40): 675-9

DOI: 10.3238/arztebl.2008.0675 